\title{
Old Insights and New Approaches: Fertility Analysis and Tempo Adjustment in the Age-Parity Model
}

\author{
Hans-Peter Kohler and José Antonio Ortega
}

\begin{abstract}
In this article we provide an overview of traditional and recent methods for the investigation of period fertility, emphasising in particular aspects of the analysis that are relevant in contemporary low and lowest-low fertility contexts. For this purpose, we present a new approach that integrates traditional measures of fertility, such as the TFR, in a versatile manner with $(a)$ the tempo adjustment of fertility that corrects for distortions due to the rapid postponement of fertility, $(b)$ life-table measures of fertility that eliminate influences caused by the parity composition of the population, and (c) methods for cohort completion and projection that provide a consistent and demographically correct mapping of recent period fertility patterns on the future childbearing behaviour of women still in their childbearing years.
\end{abstract}

\section{Introduction}

Demographic trends in contemporary developed countries are frequently characterised by a low level of fertility and a rapid postponement of childbearing. In addition to posing important social, economic and demographic challenges, these trends have also prompted demographers to reconsider important methodological issues related to the measurement of fertility. In particular, two aspects have deserved considerable attention in recent research: First, when fertility is being delayed or anticipated, period measures can be substantially different from cohort measures during extended periods. The difference between these levels is the tempo effect or tempo distortion. Second, when fertility behaviour is parity dependent, as is the case in low fertility contexts, period fertility needs to be studied in connection with the period parity distribution of women. While various methods have been developed to address these two issues, such as the adjusted total fertility rate (Bongaarts and Feeney 1998) or parity-progression ratios and fertility tables (Feeney and Yu 1987; Lutz 1989), there has been no integration of these approaches. Nevertheless, this integration into a unified approach to the measurement of fertility is desirable, particularly in applications investigating low fertility contexts with rapid postponement of childbearing and markedly different childbearing trends across parity.

In this paper we discuss several established and new demographic methods that 
provide an integration of tempo adjustment and parity-specific analyses based on fertility tables. Our presentation is based on a specific model of fertility that has a long tradition in demography: the age and parity fertility model (e. g., Park 1976; Quensel 1939; Rallu and Touleman 1994; Whelpton 1946). In combination with tempo adjustment, which was introduced for the age and parity model by Kohler and Ortega, (2002, henceforth KO) this model provides a new and unified "tool-kit" that can be developed for two related purposes. First, analyses based on tempo-adjusted fertility tables remove tempo distortions and parity composition effects from the observed period fertility pattern and therefore provide an improved indicator of the period quantum of fertility and a new decomposition of period TFR trends into changes in the quantum of fertility, the mean tempo effect, and the parity composition effect. Second, appropriate applications of fertility tables allow a demographically correct and consistent projection of the level, timing and distribution of the completed fertility of cohorts who have not finished childbearing, conditional on the future paths of quantum and tempo.

\section{The age and parity fertility model}

Demographic measures of fertility almost always require an explicit model of fertility behaviour that specifies the determinants of childbearing. This dependence on an explicit model is particularly important in the context of tempo adjustments that are based on a counterfactual idea: what would the fertility measures have been in the absence of changes in the timing of childbearing. As Heckmann (2001), for instance, says, "in order to be precise, counterfactual statements have to be made within a model. Ambiguity in model specification implies ambiguity in the definition of counterfactuals and hence of causality" (p. 4).

In this paper we postulate that "age" and "parity" are the most important aspects determining fertility behaviour. Our analyses are therefore based on an age and parity model of fertility. While additional factors are clearly of potential relevance for fertility behaviour as well, such as the duration since the last birth, demographic models of fertility that include these aspects are often difficult to analyse and/or pose considerable problems in their empirical implementation due to high demand on the availability and quality of data. The specification of the appropriate fertility model is therefore characterised by a trade-off between model complexity, model transparency and empirical robustness. In light of this trade-off, the age and parity model of fertility is a very attractive compromise because it includes the most important dimensions of fertility behaviour, age and parity, while it maintains the analytic simplicity of life-tables and the empirical robustness associated with the use of vital registration and related aggregate population data.

The basic measure of fertility in the age and parity model are age- and parity-specific childbearing intensities (a.k.a. rates of the first kind or occurrence-exposure rates) that determine the "risk" that a woman of parity $j$ at age $a$ experiences another 
birth and progresses to parity $j+1$. We denote these intensities as $m_{j}(a)$. In this notation, and throughout this paper, the subscript $j$ therefore refers to parity, and the intensities $m_{j}(a)$ indicate the rate at which women of parity $j$ have births of order $j+1$. Formally these intensities are defined as the instantaneous probability of transition from parity $j$ to parity $j+1$ for a woman age $a$ :

$m_{j}(a)=\lim _{\Delta a \rightarrow 0} \frac{\operatorname{Pr}(\text { birth of order } j+1 \text { between ages } a \text { and } a+\Delta a \mid \text { age } a \text {, parity } j)}{\Delta a}$

While the fertility intensities can be defined for a continuous age variable as above, practical work relies on a discrete characterisation of age intervals. Generally one-year or five-year intervals are used, and the analyses presented in this paper all use one-year intervals.

The estimation of fertility intensities is based on occurrence-exposure rates: a count of the number of births occurring to a particular set of women during a time unit divided by a measure of exposure, that is, number of person-years lived by women in the particular category during the same time unit. In the case of period analysis based on the age and parity model, we need information regarding $(a)$ the number of births during a calendar year classified by birth order and age of the mother, and $(b)$ a measure of exposure by age and parity of the women. The former information is frequently provided directly by the civil registration system. The latter information requires information about the population by parity in age in all calendar years. While few countries provide this information directly, it is generally possible to reconstruct the parity distribution over time by assuming that mortality and migration are independent from parity.

The primary advantage of childbearing intensities is that they constitute occurrence-exposure rate that relate births of order $j+1$ to women of parity $j$ who are at risk of giving birth of children of order $j+1$. This is not the case of incidence rates, where the denominator is a measure of exposure of all women in the age category. ${ }^{1}$ There is a straight relation between incidence rates and childbearing intensities. If we denote by $f_{j}(a)$ the incidence rate for women of parity $j$ and age $a$, by $E(a)$ the exposure, or person years lived, by women of age $a$ irrespective of parity, and by $E_{j}(a)$ the subset of person years lived, or exposure, by women who are at parity $j$, then the relation between the different type of fertility rates can be expressed as

$$
f_{j}(a)=\frac{B_{j}(a)}{E(a)}=\frac{E_{j}(a)}{E(a)} \cdot \frac{B_{j}(a)}{E_{j}(a)}=\frac{E_{j}(a)}{E(a)} \cdot m_{j}(a)
$$

where $B_{j}(a)$ is the number of births occurring to women age $a$ and parity $j$. Childbear-

1 We use the term incidence rate following the tradition of Finnäs (1980), Hoem (1978) and Borgan and Ramlau-Hansen (1985). Lotka and Spiegelman (1940) and van Imhoff (2001) have also used the term frequencies. These rates are also called rates of the second kind, reduced events or just rates. 
ing intensities can thus be converted into incidence rates via a simple multiplication of intensities with the fraction $E_{j}(a) / E(a)$ that reflects the proportion of exposure contributed by women of parity $j$ to the total.

It is important to note that incidence rates do not provide a pure measure of current fertility trends, but rather an interaction of past and current fertility trends. In particular, past births are precisely the events that determine the proportion of women who are at parity $j$ at each age $a$. If fertility is stable over time, this is not a problem, but when fertility is changing incidence rates are hard to interpret. Hence, since the goal of period analyses of fertility is to identify current characteristics of fertility behaviour in a given calendar year, childbearing intensities are preferable to incidence rates. This is especially the case during periods when fertility change is rapid, and the current fertility trends constitute a break with earlier patterns.

\section{Tempo distortions in childbearing intensities}

The tempo (or timing) and quantum of fertility are the two primary dimensions of individuals' fertility behaviour: they determine the average number of children born to women and the ages when these births occur for women of different parity. At the aggregate level these two dimensions, quantum and tempo, are intertwined. In particular, shifts in individuals' timing of childbearing, i. e., changes in the tempo of fertility, are associated with shifts in the date at which births occur. The number of births occurring in a year that is characterised by tempo changes, therefore, differs from the number of births that would have occurred in this year in the absence of the timing change. Correcting for these "missing" or "excess" births in a calendar year is therefore the basic idea behind the adjustment for tempo effects (or tempo distortions): tempo effects are defined as the proportional change in fertility rates and period fertility measures that are due to shifts in the timing of fertility. These tempo distortions affect incidence rates, childbearing intensities, and all derived measures such as TFR, etc.

Recent methods that allow the empirical identification and quantification of tempo distortions are all based on fertility models that include age, parity and period as the only determinants of fertility behaviour. In addition to sharing an underlying age and parity model of fertility, all recent adjustment procedures assume that period effects affecting the quantum of fertility in a calendar year-such as economic booms or crises, or family policy changes - exert a proportional influence on fertility rates at all ages. That is, period-specific quantum effects are assumed to increase or decrease rates by the same factor across all ages.

Important differences between adjustment procedures exist with respect to the fertility rates on which the adjustment is based. Bongaarts and Feeney (1998, henceforth BF) and Kohler and Philipov (2001, henceforth KP) use incidence rates (rates of the second kind), while KO have proposed to use childbearing intensities (rates of the first kind). In either case, the identification of tempo changes is derived from 
shifts in the first moment, or in the first and second moment of the schedule of fertility rates. If the analyses use incidence rates, as in BF and KP, the first and second moments are often referred to as the period mean age at birth and variance in the age at birth. The mean age at birth, $\mu_{j}^{f}$, and the variance in the age at birth, $v a r_{j}^{f}$, are calculated respectively as

$$
\begin{aligned}
\mu_{j}^{f} & =\frac{\sum_{a} a \cdot f_{j}(a)}{\sum_{a} f_{j}(a)} \\
\operatorname{Var}_{j}^{f} & =\frac{\sum_{a}\left(a-\mu_{j}^{f}\right)^{2} \cdot f_{j}(a)}{\sum_{a} f_{j}(a)},
\end{aligned}
$$

in the case when age $a$ is given as the age attained during a calendar year. ${ }^{2}$ If the analyses are based on childbearing intensities, as in $\mathrm{KO}$, the parity-specific intensity schedule mean age and variance, denoted $\mu_{j}^{m}$ and $V a r_{j}^{m}$, are obtained by replacing the incidence rates $f_{j}(a)$ in Eqs. (2-3) with the corresponding childbearing intensities $m_{j}(a)$.

The measurement of tempo distortions has a short history. Bongaarts and Feeney (1998) (BF) introduced the concept of the tempo-adjusted total fertility rate, denoted TFR', based on a simple model of fertility change that allows for shifts of the incidence rate schedule to younger or older ages over time. In the BF model, tempo changes are therefore constant across all ages and the shape of the incidence rate schedule is invariant over time. BF show that tempo adjustment in this model is feasible in a manner quite similar to Ryder's (1964) translation formula for the linear case, and they establish that tempo distortions are proportional to $\left(1-r_{j}^{f}\right)$, where $r_{j}^{f}$ is the annual increase in the period mean age at childbearing for a given birth order.

The introduction of the tempo-adjusted total fertility rate in BF has spurred a considerable controversy about the appropriateness and usefulness of this procedure (Bongaarts and Feeney 2000; Kim and Schoen 2000; Schoen and Jonsson 2003; van Imhoff and Keilman 2000). While there is a broad agreement that the BF adjustment is innovative, simple and useful as a first approximation, some of its problems have led to reformulation and extensions. Kohler and Philipov (2001) (KP), for instance, have extended the BF adjustment so that tempo changes $r_{j}^{f}(a)$ can be different for each age and parity. Specifically, the tempo change $r_{j}^{f}(a)$ in KP can vary with age in a systematic manner as

$$
r_{j}^{f}(a)=\gamma_{j}^{f}+\delta_{j}^{f} \cdot\left(a-\bar{a}_{j}^{f}\right)
$$

where $\bar{a}_{j}^{f}$ is the mean age of the adjusted incidence rate schedule, $\gamma_{j}^{f}$ is the mean change that implies increases or decreases in the mean age of the adjusted schedule

2 When using age-period or age-cohort incidence rates we have to add 0.5 to the mean age. When using age at the beginning of the year we have to add 1 . 
by an annual amount of $\gamma_{j}^{f}$, and $\delta_{j}^{f}$ is the variance change that implies an annual proportional increase in the standard deviation of the incidence rate schedule by a factor of $\exp _{j}^{\delta}{ }_{j}^{f}$. Within the KP framework, the BF-adjusted TFR is a special case in which the tempo changes are constant across all age categories and the shape-and specifically the variance - of the fertility rate schedule does not change over time. A measure for the extent of variance changes in the KP framework can therefore be derived from the relative increase in the variance of the fertility schedule per year, quite similar to the approach taken in the BF framework to use the annual change in the mean age at birth to infer tempo changes from the trend in the mean age of the incidence rate schedule.

In addition to adjusting summary measures of fertility, such as the TFR, KP also develop the tempo adjustment on the level of age- and parity-specific fertility incidence rates, $f_{j}(a)$. At each age and parity, an adjusted age- and parity-specific fertility rate can thus be calculated as

$$
f_{j}^{\prime}(a)=f_{j}(a) /\left[1-r_{j}^{f}(a)\right]
$$

where $r_{j}^{f}(a)$ is the tempo change at age and parity $j$ that is estimated based on the annual change in the mean age at childbearing $\left(\mu_{j}^{f}\right)$ and the proportional change in the variance $\left(\operatorname{Var}_{j}^{f}\right)$ of the period incidence rate schedules (see KP for a detailed discussion).

The reliance of both the BF and KP models on incidence rates, however, is unfortunate since the inference about tempo change based on incidence rate schedules is affected by the dynamics of the parity composition of the population. This influence of the parity distribution leads to potentially non-negligible biases in the estimates of tempo distortions. In particular, fluctuations in the level, mean and variance of the incident rate schedule are not only the result of period-specific changes in fertility behaviour, but result from the interaction of present fertility behaviour (as measured by intensities) and past fertility behaviours (as present in the parity composition of the population).

The following two examples exemplify the problems that potentially result from this interaction. First, consider the case of a delay in first births combined with a reduction in quantum prior to the calendar year of interest (denoted as reference year). This is a common scenario in many countries, and it is a particularly common case when analysing lowest-low fertility countries of from a contemporary perspective. Additionally assume that the timing and quantum of fertility stabilise in the reference year and are constant in subsequent periods. This combination of $(a)$ a decline in quantum associated with a delay of childbearing prior to the reference year and $(b)$ a subsequent constant pattern of fertility timing and quantum implies that many women in the reference year had their first births when the fertility rates were higher and births took place earlier. As a consequence, the proportion of women at parity zero at older ages is "out of equilibrium" with too few women in that category as compared to a situation where the fertility quantum and tempo had been constant at their present levels also prior to the reference year. As time progresses, therefore, the 
proportions of older women at parity zero will increase and there will be a shift in the mean age at birth for parity one and above. This shift occurs despite the fact that there are no further changes in the birth intensities, or the parity-specific quantum and tempo, subsequent to the reference year. An observer who is not aware of the joint influence on incidence rates of population composition (or past fertility behaviour) and present fertility behaviour (as reflected in period childbearing intensities) might interpret this shift in mean age at first birth as a tempo change and implement the BF or $\mathrm{KP}$ adjustment of the total fertility rate. In fact, however, this adjustment erroneously corrects for changes in the timing of fertility in a situation where there have been none: our example assumes that childbearing intensities, and thus parity-specific tempo and quantum, are constant during and after the reference year.

Second, consider a situation that arises through a drastic decline in the quantum of first-birth fertility, while the quantum at higher parities remains unaltered as compared to earlier periods. This new pattern implies that fewer young women attain parity one. As a consequence, the mean age at second birth as estimated from period incidence schedules will increase over time because there is a declining number of young women who are at risk of having a second child. This increase in the mean age, however, is not due to a change in fertility behaviour of women who are at parity one-it merely results from the compositional change caused by a declining fraction of women who experience a first birth. Moreover, in the application of the BF or KP adjustment of the TFR the increase in mean age is interpreted as a tempo change for second births, resulting in an increase of the adjusted as compared to the observed total fertility rate. As in our first example, however, this adjustment is erroneous because there have been no changes in parity-specific fertility behaviour for second births, and the observed change in the mean age of the period incidence rate schedule is only due to the interaction of tempo and quantum across different parities in determining these rates. Similar examples can also be devised for the calculation of variances, where the inference variance changes based on incidence rates can also be misleading.

In order to avoid the above problems associated with the use of incidence rates in the adjustment of fertility, Kohler and Ortega (2002) (KO) proposed an extension of tempo adjustment to an age and parity model in which age and parity-specific childbearing intensities are the basic measure of fertility. Since these intensities constitute occurrence-exposure rates, distortions due to shifts in the parity distribution of the population are absent. Changes in the mean age $\mu_{j}^{m}$ and variance $\operatorname{Var}_{j}^{m}$ of the intensity schedules over time can therefore provide an inference of timing changes that is not affected by changes in the parity distribution of the population. Based on this insight, KO specify an age-specific tempo change $r_{j}^{m}(a)$ that is analogous to the KP variance effect framework as

$$
r_{j}^{m}(a)=\gamma_{j}^{m}+\delta_{j}^{m} \cdot\left(a-\bar{a}_{j}^{m}\right)
$$

where $\bar{a}_{j}^{m}$ is the mean age of the adjusted intensity schedule, $\gamma_{j}^{m}$ is the mean change and $\delta_{j}^{m}$ is the variance change that affect the mean and variance of the intensity 
schedule over time. ${ }^{3}$ Once an estimate of the age- and parity-specific tempo change $r_{j}^{m}(a)$ has been obtained from the evolution of mean and variance of intensity schedules over time, tempo-adjusted childbearing intensities can be calculated from the observed intensities as

$$
m_{j}^{\prime}(a)=m_{j}(a) /\left(1-r_{j}^{m}(a)\right),
$$

that is, in an identical manner as in the KP-extension of the BF framework for tempo adjustment.

Tempo-adjusted childbearing intensities then provide a versatile building block of a broad range of fertility measures. For instance, the relation between incidence rates and childbearing intensities in Eq. (1) suggests an alternative definition of tempo-adjusted incidence rates that is derived from tempo-adjusted childbearing intensities $m_{j}^{\prime}(a)$ as

$$
f_{j}^{\prime \prime}(a)=\frac{E_{j}(a)}{E(a)} \cdot m_{j}^{\prime}(a) .
$$

Tempo-adjusted incidence rates are thus obtained by combining the observed parity distribution in a calendar year with tempo-adjusted childbearing intensities that remove the tempo distortions from fertility rates (net of influences resulting from changes in the parity distribution). The tempo-adjusted incidence rates in Eq. (4) are therefore preferable to the adjusted incidence rates in the BF and KP framework since $(a)$ they avoid the above problems due to the estimation of tempo changes from incidence rates, and $(b)$ they have a desirable interpretation as the incidence rates that would have been observed at age $a$ if there had been no tempo change in a calendar year, conditional on the parity distribution observed in the period.

The adjusted incidence rates $f_{j}^{\prime \prime}(a)$ and childbearing intensities $m_{j}^{\prime}(a)$ are illustrated in Figure 1 for Italy and the Czech Republic for the year 1995. Table 1 reports the underlying estimates for the sum, denoted $q_{j}^{m}$, the mean $\mu_{j}^{m}$, and the variance $\operatorname{Var}_{j}^{m}$ of the adjusted intensity schedules along with the annual mean change and variance change estimated for the year 1995. Table 1 shows that the mean change in both Italy and the Czech Republic is largest for first births, and it is considerable larger in the Czech Republic than in Italy due to a faster pace of fertility postponement. At the same time, there is almost no tempo change for second births in the Czech Republic,

3 In many instances, variance effects can presumably be ignored in terms of their overall influence on adjusted summary measures of fertility (such as the TFR), and tempo changes can often be assumed to be equal across all ages in a calendar year (as is the case in the BF framework). In particular, variance effects are present if tempo changes vary across age. If the tempo changes $r_{j}^{m}(a)$ are relatively smaller below and relatively larger above the intensity schedule mean age, that is, if variance effects are present and $\delta_{j}^{m}>0$, the standard deviation in the intensity schedule increases over time. The standard deviation declines over time if $\delta_{j}^{m}<0$. The need to consider such variance effects arises because changes in the timing of fertility do not necessarily imply parallel shifts in the parity-specific schedules of childbearing intensities (or incidence rate schedules). 
Table 1:

Sum, Mean age and variance of adjusted intensity schedule in 1995 for Italy and the Czech Republic, and estimated man change and variance change

\begin{tabular}{|l|r|r|r|r|r|c|}
\hline & \multicolumn{3}{|c|}{ Italy } & \multicolumn{3}{c|}{ Czech Republic } \\
\hline Parity & 0 & 1 & 2 & 0 & 1 & 2 \\
\hline Sum $q_{j}^{m}$ & 1.65 & 2.79 & 0.97 & 2.36 & 2.10 & 0.63 \\
\hline Mean $\mu_{j}^{m}$ & 31.03 & 27.37 & 26.74 & 27.00 & 26.37 & 24.38 \\
\hline Variance aar $_{j}^{m}$ & 5.33 & 6.29 & 5.89 & 5.21 & 5.34 & 5.17 \\
\hline Mean change $\gamma_{j}^{m}$ x 10 & 2.03 & 1.22 & -0.25 & 3.30 & 0.34 & -1.59 \\
\hline Variance change $\delta_{j}^{m} \times 1000$ & 3.15 & 6.25 & 6.20 & 1.19 & 16.48 & -5.65 \\
\hline
\end{tabular}

Note: In contrast to incidence rates, it is possible, as in the above examples, that the mean age for intensity schedules is highest for parity zero and then declines for higher parities.

and there is even a modest anticipation of fertility for third births. The variance change is higher for second than for first births in both countries, and in Italy it remains high also for third births while there is a reduction in the variance in the Czech Republic for third births. Figures 1(a, c) also reflect this pattern. The adjusted intensities substantially exceed the observed intensities for first births, while the differences are substantially smaller for second and third births. Moreover, higher parities also reveal the presence of variance changes. This is most clearly visible for second births in the Czech Republic, where there is a marked annual increase in the variance $\left(\delta_{1}^{m}=0.016\right)$. As a consequence, the age-specific tempo change $r_{1}^{m}(a)$ is even negative at very low ages, indicating an anticipation of births, and the adjusted intensities are below the observed intensities. At age 24 a cross-over occurs, and above age 24 the proportional difference between the observed and adjusted intensities increases with age and the pace of postponement is most rapid for women who are at risk of a second birth at relatively old ages. Figures $1(b, d)$ additionally depict the KO-adjusted incidence rates defined in Eq. (4). The level of these incidence rates is below that of childbearing intensities since the latter result from the former by multiplying with the fraction of exposure that was contributed by women with different parities at each age (Eq. 1).

For incidence rates (Figures 1b, d) and childbearing intensities (Figures 1a, c), the tempo effects can be interpreted as the percentage by which each observed rate must be adjusted to remove tempo distortions. A comparison of the schedules in Figure 1, however, reveals that even a large tempo adjustment in childbearing intensities at some age $a$ and parity $j$, which is due to marked changes in individuals' fertility behaviour at this age and parity, may have a small effect on incidence rates if the proportion of exposure contributed by parity $j$ women at this age is low. In addition, the comparison between Italy and the Czech Republic also reflects the different age-patterns of fertility between Southern European and CEE countries, where the latter still exhibit substantially younger mean ages of period incidence schedules. 
Figure 1.

Adjusted and observed schedules of childbearing intensities and incidence rates in Italy and the Czech Republic, 1995

(a) Italy: childbearing intensities

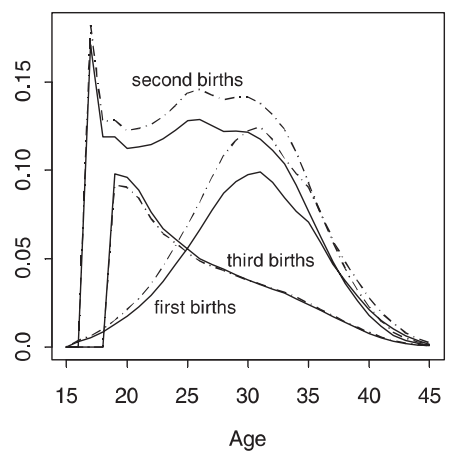

(c) Czech R.: childbearing intensities

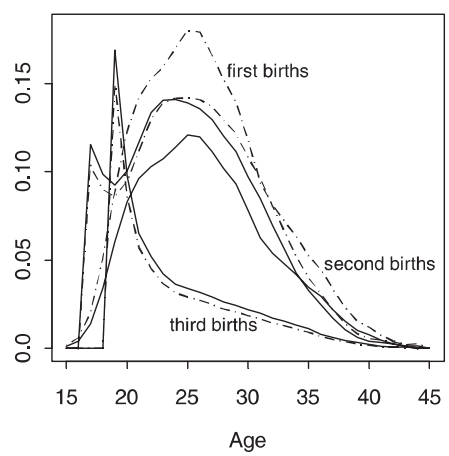

(b) Italy: incidence rates

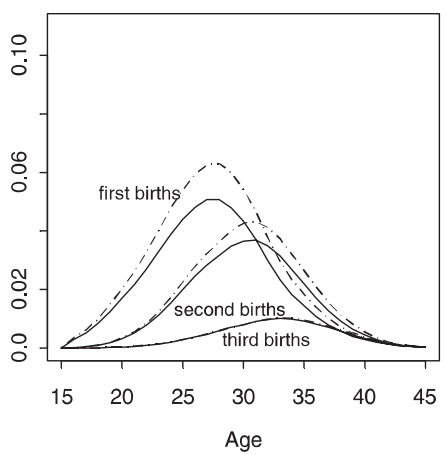

(d) Czech R.: incidence rates

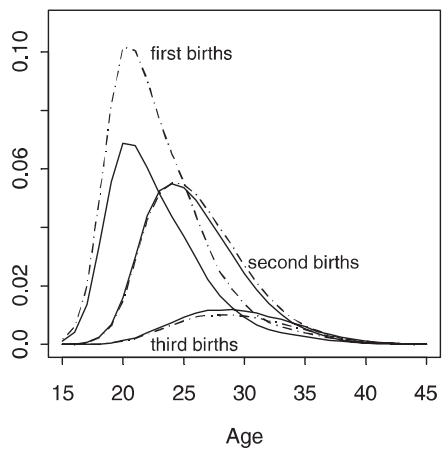

\section{Life-table measures of period fertility}

The goal of analysing period fertility is to describe the fertility behaviour of a synthetic cohort that experiences the fertility rates - either specified as childbearing intensities or as incidence rates - that prevail in a given calendar year. In this paper we particularly focus on life-table measures to describe period fertility. Life-table measures are probably the central tool of demographic analysis, and most commonly used measures in demography such as life expectancy, total fertility rate, parity progression ratios, net reproduction ratios, can all be interpreted as life-table measures. Period life-table measures are also synthetic measures since they do not refer to a real cohort but to a synthetic cohort (Vallin and Caselli 2001). This synthetic cohort is assumed $(a)$ to experience the observed or adjusted period rates over its life-course, and (b) not to be subject to mortality (exceptions are measures such as the net reproduction rate that include mortality). Life-table measures thus provide a unifying framework for the study of both period and cohort demographic indicators, and they are particularly suitable to the analyses of fertility within the age and parity model. 
The innovation in our discussion of life-table measures of fertility is the combination of these measures with the tempo adjustment of childbearing intensities discussed in Sections 2-3. ${ }^{4}$ The analysis is then based on fertility tables that constitute a special case of multiplicative life-tables in the sense that multiplicative calculations based on childbearing intensities provide the probabilities of subsequent transitions towards higher parities in the age and parity model. Standard fertility measures based on incidence rates, such as the TFR, are additive because they are obtained by adding age-specific fertility rates over age (and/or over birth order). Fertility tables have been previously studied by Park (1976), Lutz (1989), Rallu and Toulemon (1993a), Giorgi (1993) and De Simoni (1995), and they have been developed as a useful tool to organise childbearing intensities and to compute summary measures of fertility. Typically, a fertility table will include columns for $(a)$ the number of women, by age, at different parities $j, j=0, \ldots, J(b)$ the number of births of order $j+1$ that occur to women of parity $j$ between age $a$ and $a+1$, and (c) the probability that a woman of age $a$ and parity $j$ experiences an additional birth prior to age $a+1$. Programs to calculate fertility tables and the related measures discussed in this paper are available at http://www.ssc.upenn.edu/ hpkohler. ${ }^{5}$

The basic measure of fertility in the age and parity framework, denoted ${ }_{n} F_{j}\left(a_{0}, a_{1}\right)$, is the probability that a woman who is of age $a_{0}$ and parity $j$ experiences at least $n$ additional births between exact ages $a_{0}$ and $a_{1}$. On the aggregate level, this probability is equal to the proportion of women of parity $j$ and age $a_{0}$ who experience at least $n$ addition births prior to age $a_{1}$. This probability is particularly simple to calculate for one additional birth, where it is also denoted as the conditional parity progression probability $p_{j}\left(a_{0}, a_{1}\right)$, as

$$
\begin{aligned}
p_{j}\left(a_{0}, a_{1}\right)=F_{1} F_{j}\left(a_{0}, a_{1}\right) & =1-\prod_{a=a_{0}}^{a_{1}-1} \exp \left[-m_{j}^{\prime}(a)\right] \\
& =1-\exp \left[-\sum_{a=a_{0}}^{a_{1}-1} m_{j}^{\prime}(a)\right] .
\end{aligned}
$$

The conditional parity progression probability $p_{j}\left(a_{0}, a_{1}\right)$ in Eq. (5) is thus equal to the probability that a woman who is of age $a_{0}$ and parity $j$ experiences another birth and progresses to parity $j+1$ prior to age $a_{1}$. This parity progression probability is "conditional" because it depends on the initial age and parity of the woman.

When the second age limit in expression (5) is set to the upper limit of childbearing ages $\omega$ (say, age 49), the probability ${ }_{n} F_{j}(\alpha, \omega)$, or shorthand ${ }_{n} F_{j}(\alpha)$ equals, Park's (1976) lifetime probability of at least $n$ additional births for a woman who is age $a$ and parity $j$. This lifetime probability can also denoted as $p_{j}(a)$ for the special case of $n=1$, that is, in the special case when it measures the life-time probability

4 Of course, life-table measures of fertility can also be calculated based on standard childbearing intensities that are not adjusted for tempo distortions.

5 The programs are written in the freely available $\mathrm{R}$ package for statistical analyses and graphics; see http://www.r-project.org. An alternative method for the calculation of fertility tables is the LIPRO program by van Imhoff and Keilman (1991). 
${ }_{1} F_{j}(\alpha, \omega)$ of at least one additional birth after age $a$ for a woman who is at parity $j$.

The sum of all adjusted intensities is denoted in $\mathrm{KO}$ as the parity-specific level effect, $q_{j}$, defined as $q_{j}=\sum_{a=\alpha}^{\omega} m^{\prime}(a)$, and it is related to the conditional parity progression probability as $q_{j}=-\log \left(1-p_{j}(\alpha)\right)$, where $\alpha$ is the lower limit of childbearing ages (say, age 15).

While the calculation of the progression probabilities to the next child in Eq. (5) is relatively simple, the application of life-table fertility measures to several parities is more complicated since it needs to account for the different transitions to the first, second, third, ...birth. Fertility tables provide a useful way of organising and presenting these calculations. In general, a fertility table will therefore include the conditional parity progression probabilities $p_{j}(a, a+1)$, the number of women of parity $j$ and exact age $a, D_{j}(a)$, and the number of births occurring to those women between ages $a$ and $a+1, b_{j}(a, a+1)$.

The first step in building a fertility table is the conversion of childbearing intensities to transition probabilities. Although the simplest approach is the direct estimation of birth probabilities instead of intensities as in Rallu and Touleman (1993b), this is not easily combined with tempo adjustments. The alternative is the simple exponential formula derived from Eq. (5) that yields the tempo-adjusted age- and parity-specific probability of birth, $p_{j}(a, a+1)$, as

$$
p_{j}(a, a+1)=1-\exp \left[-m_{j}^{\prime}(a)\right] \text {, }
$$

where $m_{j}^{\prime}(a)$ is the adjusted childbearing intensity at parity $j$ and age $a$. The tempo-adjusted age- and parity-specific probability of birth, $p_{j}(a, a+1)$ in Eq. (6) can then be used to calculate the remaining life-table measures. In particular, the births $b_{j}(a, a+1)$ and the parity distribution $D_{j}(a)$ table are iteratively calculated over age using the formulas

$$
\begin{aligned}
b_{j}(a, a+1) & =D_{j}(a) \cdot p_{j}(a, a+1) \\
D_{j}(a+1) & =D_{j}(a) \cdot\left(1-p_{j}(a, a+1)\right)+D_{j-1}(a) \cdot p_{j-1}(a, a+1) \\
& =D_{j}(a)-b_{j}(a, a+1)+b_{j-1}(a, a+1)
\end{aligned}
$$

with the initial conditions $D_{0}(\alpha)=N$ and $D_{j}(\alpha)=0$ for $j>0$, where $N$ is the radix of the fertility table that equals the size of the synthetic cohort. ${ }^{6}$

6 In this iterative calculation of the fertility table, it is common that the last parity category, $J$, includes parities $J$ and above. In this case, the formulas are slightly different for this last parity and are given by

$$
\begin{aligned}
b_{J}(a) & =\frac{1}{2}\left[D_{J}(a)+D_{J}(a+1)\right] \cdot \frac{f_{J}(a)}{E_{J}(a) / E(a)} \\
D_{J}(a+1) & =D_{J}(a)+b_{J-1}(a, a+1),
\end{aligned}
$$

where $E_{J}(a) / E(a)$ is the fraction of exposure at age contributed by women in the last parity category $J$ and the term $f_{J}(a) E(a) / E_{J}(a)$ represents the fertility incidence rate for women conditional on being in the last parity category. 
Two examples of fertility tables based on the tempo-adjusted intensities are given in Table 2 and 3 for Italy and the Czech Republic in 1995. The primary advantage of these fertility tables is that many summary measures can be constructed directly from the table births. For instance, the numbers of births of order $j_{1}+1$ to $j_{2}+1$ occurring between age $a_{0}$ to $a_{1}$ in the synthetic cohort is defined by rectangular sums of births in the table [see also De Simoni 1995] as

$$
\begin{aligned}
b_{j_{1}, j_{2}}\left(a_{0}, a_{1}\right) & =\sum_{a=a_{0}}^{a_{1}-1} \sum_{j=j_{1}}^{j_{2}} b_{j}(a, a+1) \\
& =\sum_{j=j_{1}}^{j_{2}} b_{j}\left(a_{0}, a_{1}\right) .
\end{aligned}
$$

The sums $b_{j 1},{ }_{j 2}\left(a_{0}, a_{1}\right)$ then provide a building block for many life-table fertility measures. The most important of these fertility measures is the period fertility index. This index represents a tempo-adjusted version of the PATFR index introduced by Rallu and Touleman 1994, and it is equal to

$$
\mathrm{PF}=b_{0, J}(\alpha, \omega) / N
$$

where $J$ is the highest parity in the fertility table. The period fertility index is thus equal to the sum of all births occurring in the fertility table divided by the radix $N$.

The primary advantage of this period fertility index $(\mathrm{PF})$ is its direct interpretation in terms of synthetic cohort fertility: it is equal to the total fertility of women in a synthetic cohort that experience the tempo-adjusted childbearing intensities in a calendar year throughout their childbearing ages. This period fertility index is important because it provides a summary measure of the overall quantum of fertility in the age and parity model. Its equivalent on the parity-specific level is conditional parity progression probability $p_{j}$. These indicators of the quantum of fertility are free both of tempo and compositional distortions, as is desirable for quantum measures, since their calculation is based on tempo-adjusted childbearing intensities instead of incidence rates. $^{7}$

Several additional fertility measures can be derived from the fertility table. For instance, the period fertility index can also be calculated based on Park's (1976) lifetime probability of $n$ additional births for women at the beginning of their reproductive years as $\mathrm{PF}=\sum_{n=1}^{J} \quad{ }_{n} F_{0}(\alpha, \omega)$, where Park's lifetime probability of $n$ additional births is calculated as ${ }_{n} F_{0}(\alpha, \omega)=b_{n-1, J}(\alpha, \omega) / N$. Parity progression probabilities from parity $j$ to $j+1$ can also be directly obtained the lifetime birth probabilities ${ }_{j+1} \pi_{j}={ }_{j+1} F_{0}(\alpha, \omega) / F_{j}(\alpha, \omega)$. A further useful measure is also the cumulated sum $\mathrm{CF}(a)=b_{0, J}(\alpha, a-1) / N$ that provides the cumulative fertility up to age $a$.

7 Fertility tables are generally calculated for women who are at parity zero and at the beginning of their childbearing years (age $\alpha$ ). While convenient and commonly performed, this choice is merely a special case of a fertility table. In particular, alternative choices are useful to calculate the additional birth probability for women who are age $a$ and parity $j$, denoted ${ }_{n} F_{j}(a)$, suitable in the context of cohort completion. The calculation of these additional birth probabilities require similar calculations as those in Tables 2 and 3, but performed for women who are initially of age $a$ and parity $j$ and followed only until age $\omega$ and the birth order $j+n$ (or alternatively, until parity $J$ ). KO denote this subgroup of women as the synthetic cohort age $a$ and parity $j$. 


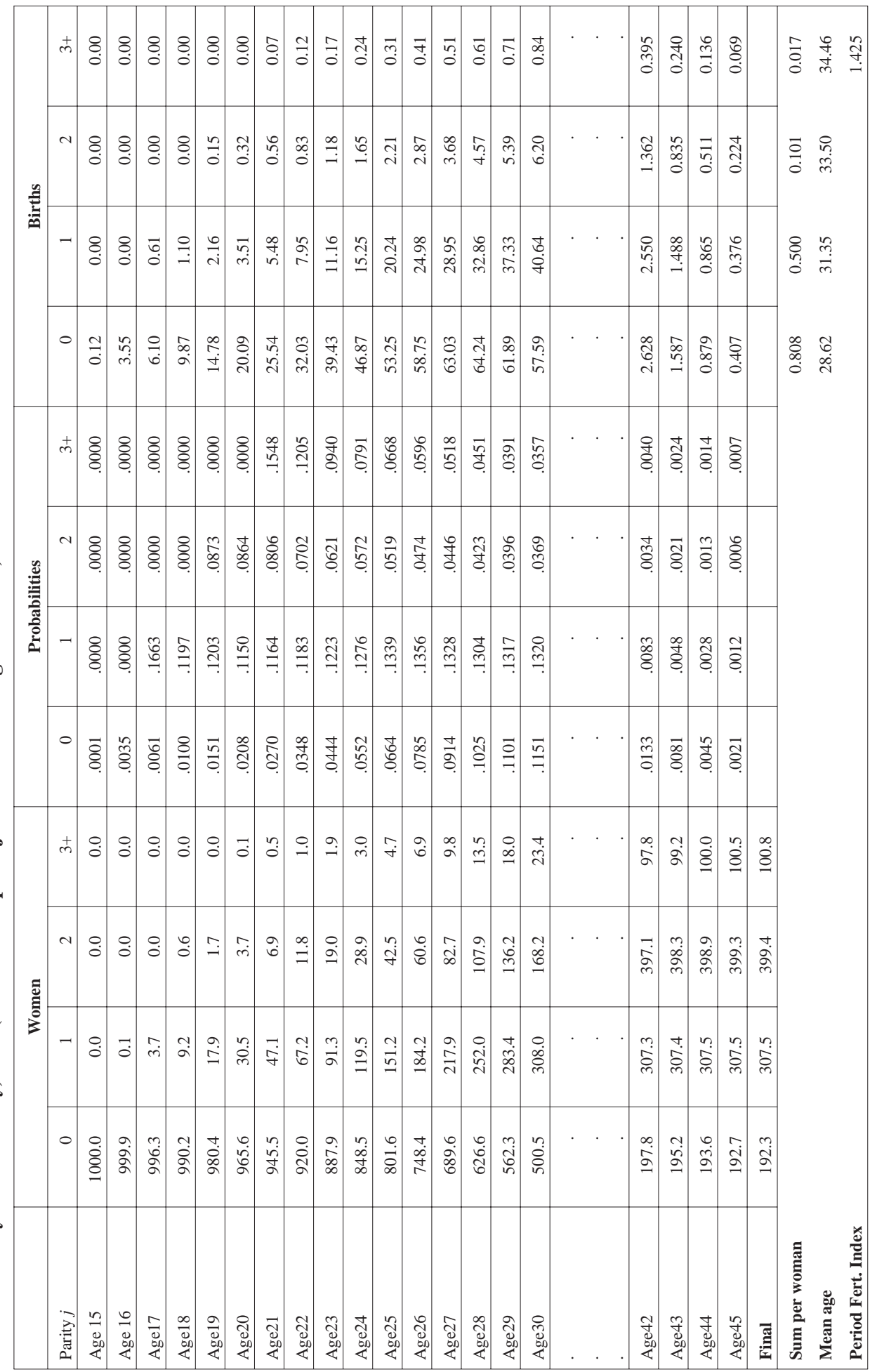




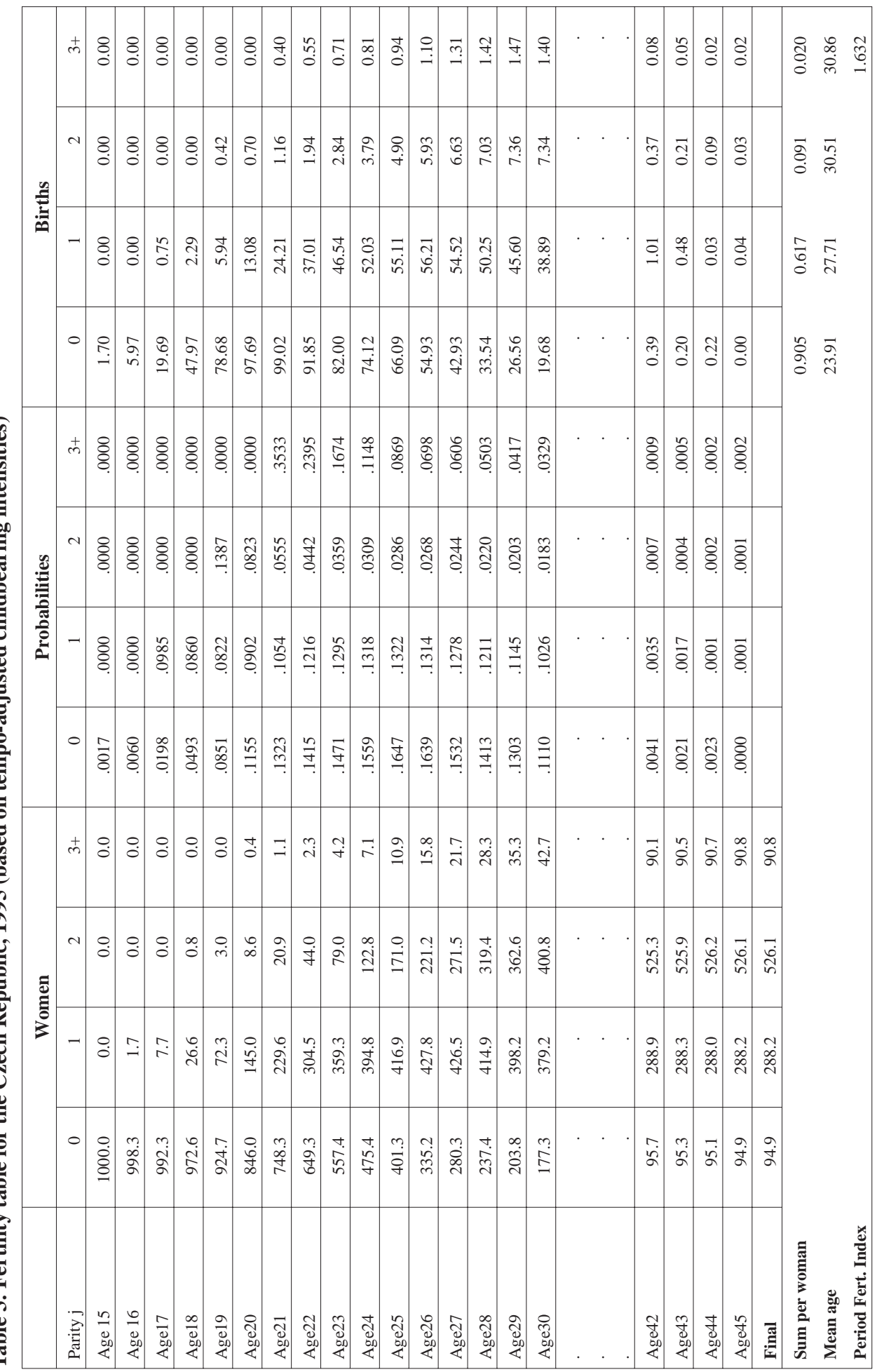


Figure 2:

Cumulated proportions of women at different parities in Italy and Czech Republic based on 1995 tempo-adjusted childbearing intensities

(a) Italy

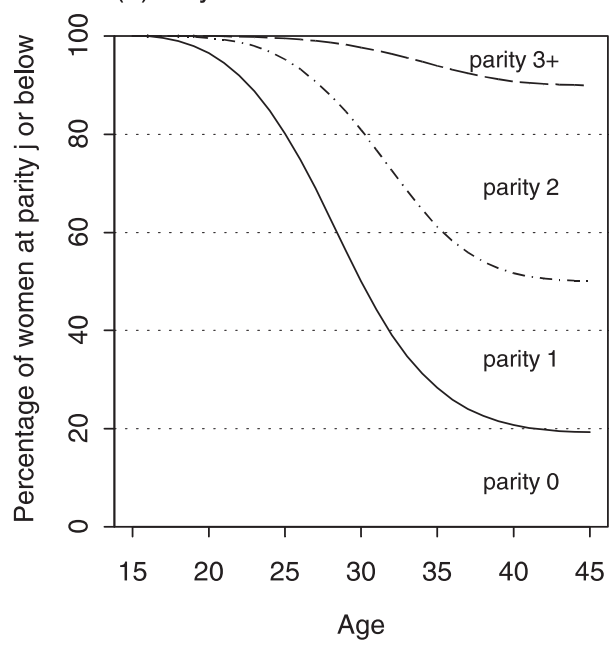

(b) Czech Republic

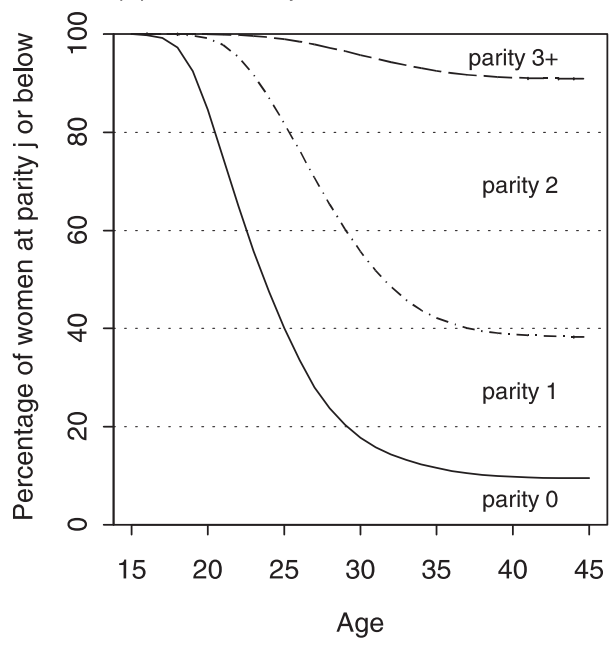

Park's lifetime probabilities of at least $j+1$ births for Italy and the Czech Republic are shown in the row "sum per women" in Tables 2-3. In the Italian example, the proportion of women having an additional birth at parity and are equal to .81 and .5 , which implies a childlessness of about $19 \%$ and a parity progression probability ${ }_{2} \pi_{1}$ of .62. Only about $10 \%$ of women have a third child, and fourth births are almost absent in the synthetic cohort. The calculations for the Czech Republic yield lifetime birth probabilities of one, two and three children at $0.91,0.62$ and 0.09 , respectively.

The period fertility index obtained from the fertility tables for Italy and the Czech Republic (Tables 2 and 3) equals 1.43 (Italy) and 1.63 (Czech R.), indicating that a synthetic cohort experiencing the 1995 tempo-adjusted childbearing intensities would have 0.2 children more in the Czech Republic as compared to Italy.

The distribution of women by parity at the different ages, $D_{j}(a)$, also follows directly from the fertility table (see also Figure 2). If the childbearing intensities remained constant long enough-which implies that there are no quantum or tempo changes at any parity after the year for which the fertility table is calculated - these proportions would be the ones observed in the population. The $D_{j}(a)$ proportions therefore reflect the equilibrium distribution that is defined as the parity distribution by age in the stable population. The final parity distribution attained by women at the end of childbearing in the stable population is reflected in the last row of the first four columns in Tables 2 and 3. In Italy, the final proportion of women at parity zero, one, two and three or more in the 1995 synthetic cohort are $0.19,0.31,0.40$ and .1, respectively, indicating that especially the progression probability after the first child is low. About $50 \%$ of women therefore remain at parities zero or one. The final parity 
distribution in the Czech 1995 synthetic cohort is $0.09,0.29,0.53$ and 0.09 , which is consistent with the substantially higher parity progression ration from the first to the second child, and a low probability to have a third child. Two children, therefore, emerges as the most common parity in the Czech synthetic cohort, which is in stark contrast with Italy where there is a more even distribution among parities zero, one, two and three or more.

It is also possible to obtain birth-interval measures, since the mean birth interval from parity $j$ to parity $j+1$ is equal to the difference between the mean age at birth at parity $j+1$ minus the mean age at birth at parity $j$ for the women who had additional children. This can be computed by splitting the number of births between age $a$ and $a+1$ in the general fertility table into two columns: those by women that had additional children, ${ }_{+} b_{j}(a, a+1)$, and those by women that remained at parity $j+1$, ${ }_{1} b_{j}(a, a+1)$. They are given respectively by

$$
\begin{aligned}
& +b_{j}(a, a+1)=b_{j}(a, a+1) \cdot p_{j}(a, \omega) \quad \text { and } \\
& { }_{1} b_{j}(a, a+1)=b_{j}(a, a+1) \cdot\left[1-p_{j}(a, \omega)\right],
\end{aligned}
$$

where $p_{j}(a, \omega)={ }_{j+1} F_{j}(\alpha, \omega)$ is the additional birth probability defined in Eq. (5) that a women who is of age $a$ and parity $j$ experiences at least one additional birth. Using the above separation of births into ${ }_{+} b_{j}(a, a+1)$ and ${ }_{1} b_{j}(a, a+1)$, we can then estimate the mean ages at birth for women who progress to the $j+1$ st child and those who do not and remain at parity $j$. Subtracting the former from the mean age at the next birth, we obtain the mean birth interval for the transition for parity $j$ to $j+1$ (Feichtinger 1987). In Table 4 we show an example of the calculations. We observe that those women who progress to second birth were much younger when having their first birth than those that did not (27 versus 31.8 years in Italy, and 22.9 versus 26.5 in the Czech Republic). The same applies for progression to third birth. Because of this, the difference between the overall mean ages at birth would be an underestimate of the birth interval in the synthetic cohort. The mean birth intervals obtained are therefore 4.38 years from first to second birth and 4.87 from second to third in Italy, and 4.84 and 5.12 in the Czech Republic.

\section{Period fertility analysis}

Period measures of fertility are important because they can be linked to the number of births in a calendar year. In particular, whenever we are interested in the consequences of period fertility, it is usually the number of births that matters (Calot 2001 a,d; Schoen and Jonsson 2003; Touleman 2001, van Imhoff 2001): it is the number of births that determines the size of future generations and thus the impact of current period fertility behaviour on future labour market conditions, shortages in the housing market, or strains on pension systems due to ageing, etc.

The basic purpose of demographic analysis in this context is the separation of the 
different factors contributing to the number of births in a calendar year. In this section we discuss several period fertility measures that are suitable for period analyses, and we suggest a new decomposition of period fertility that provides a link between the different layers of influences on the number of births: age composition, parity distribution, and tempo effects.

Table 4:

Mean birth intervals, first to second and second to third births for Italy and the Czech Republic (estimated from 1995 tempo-adjusted childbearing intensities)

\begin{tabular}{|l|c|c|c|c|}
\hline & \multicolumn{2}{|c|}{ Italy } & \multicolumn{2}{c|}{ Czech Republic } \\
\hline $\begin{array}{l}\text { Women } \\
\text { progressing to } \\
\text { next child }\end{array}$ & $\begin{array}{c}\text { Women not } \\
\text { progressing to } \\
\text { next child }\end{array}$ & $\begin{array}{c}\text { Women } \\
\text { progressing to } \\
\text { next child }\end{array}$ & $\begin{array}{c}\text { Women not } \\
\text { progressing to } \\
\text { next child }\end{array}$ \\
\hline Transition first to second child & 31.85 & 22.87 & 26.52 \\
\hline Mean age at $1^{\text {st }}$ birth & 26.97 & & 27.71 & \\
\hline Mean age at $2^{\text {nd }}$ birth & 31.35 & & 4.84 & \\
\hline Birth interval & 4.38 & 32.16 & 25.38 & 28.19 \\
\hline Transition second to third child & 28.63 & & 30.51 & \\
\hline Mean age at $1^{\text {st }}$ birth & 33.50 & & 5.12 & \\
\hline Mean age at $2^{\text {nd }}$ birth & 4.87 & & & \\
\hline Birth interval &
\end{tabular}

In a static context where the timing and level of fertility remain constant over long periods of time, the life-table measures of period fertility discussed in the previous section and the conventional period fertility measures yield identical results. In this stable case, for instance, the TFR is equal to the period fertility index PF. While this stable scenario may be interesting for formal demographic analyses, it is not a good representation of reality. Fertility rates are clearly not constant over time, and in particular, the level as well as the tempo of period fertility are subject to-sometimes even very rapid - changes. In this context of changing fertility patterns, the equality of life-table based measures and incidence-rate based measures of period fertility no longer holds.

Despite our preference for life-table measures of fertility that are based on childbearing intensities (see Section 3), we begin our discussion of period fertility analyses with the total fertility rate (TFR). It is well known that the rationale for introducing the total fertility rate is the fact that it is not affected by the composition of the population by age (e. g. Kuczynski 1932). The TFR is defined as the sum of age-specific fertility rates for all ages. It has been defined at the parity-specific level as the sum of the incidence rates for a particular parity:

$$
\begin{aligned}
& \mathrm{TFR}_{j}=\sum_{a} f_{j}(a) \\
& \mathrm{TFR}_{j}=\sum_{j} \mathrm{TFR}_{j}
\end{aligned}
$$


The relationship between the TFR and the number of births has extensively been studied by Ryder $(1964,1980)$ and Calot $(1984,1985)$. Calot, for instance, uses the term mean generation size for the factor that translates the TFR into births, while Ryder (1980) denotes as age distribution factor the factor that converts the TFR into the crude birth-rate. Obviously, mean generation size is equal to the age distribution factor multiplied by the average population size (or mean exposure).

The second factor influencing the number of births in a given calendar year, not reflected in previous analyses, is due to tempo effects that arise from changes in individuals' timing of fertility. This influence of tempo effects can be assessed using an appropriately tempo-adjusted period fertility measure that is comparable to the observed TFR. In the context of the age and parity model of fertility, it is preferable not to use the BF-adjusted TFR, but instead define a KO-adjusted TFR that is based on the tempo-adjusted incidence rates $f_{j}^{\prime \prime}(a)$ (see Eq. 4) as

$$
\begin{aligned}
\mathrm{TFR}_{j}^{\prime \prime} & =\sum_{a} f_{j}^{\prime \prime}(a) \\
\mathrm{TFR}^{\prime \prime} & =\sum_{j} \mathrm{TFR}_{j}^{\prime \prime} .
\end{aligned}
$$

This KO-adjusted total fertility rate has the interpretation as the TFR that would have been observed in a calendar year if there had been no changes in the timing of fertility in that year, conditional on the parity distribution of the population in the period. That is, the TFR has the interpretation that is desired for the adjusted TFR, and it avoids any distortions in the adjustment that occur if incidence rates are used for the estimation of tempo changes. Since the KO-adjusted TFR is based on childbearing intensities it entails three key advantages: first, it provides a more direct link to life-table measures and individual fertility behaviour (see below); second, it is equal to the period fertility index if the age-distribution in a calendar year is equal to the equilibrium distribution associated with the period tempo-adjusted intensities; and third, the underlying inference of the tempo change is based on intensity schedules-instead of incidence-rate schedules as in BF-which avoids potentially misleading estimates due to compositional influences.

The overall influence of tempo effects on the period TFR can then be measured via a mean tempo effect, denoted $r$, that is defined as

$$
r=1-\frac{\mathrm{TFR}}{\mathrm{TFR}^{\prime \prime}}
$$

where TFR is the observed and TFR" is the KO-adjusted period total fertility rate. This mean tempo effect is interpreted as the fraction of births that "missing" $(r>0)$ or "in excess" $(r<0)$ in a calendar year due to the fact that there have been changes in individuals' fertility timing during that year. The mean tempo effect is zero if there are no tempo changes across all parities, or if parity-specific tempo changes compensate each other. Moreover, this mean tempo effect can also be seen as a weighted average of all parity- and age-specific tempo effects in childbearing intensities, and it can be calculated separately for each parity or age-parity combination (for a further discussion, see Ortega and Kohler 2002). 
Table 5:

Summary period fertility indicators for Italy and Czech Republic, 1995

\begin{tabular}{|l|c|c|c|c|c|c|}
\hline & \multicolumn{3}{|c|}{ Italy } & \multicolumn{3}{c|}{ Czech Republic } \\
\hline & First births & Second births & All births & First births & Second births & All births \\
\hline Observed TFR & 0.61 & 0.43 & 1.18 & 0.56 & 0.51 & 1.25 \\
\hline BF-adj. TFR & 0.79 & 0.54 & 1.50 & 0.82 & 0.72 & 1.79 \\
\hline KO-adj. TFR & 0.76 & 0.50 & 1.40 & 0.82 & 0.53 & 1.52 \\
\hline
\end{tabular}

Table 5 reports the 1995 total fertility rate, the BF-adjusted TFR and the KO-adjusted TFR for first, second and all births in Italy and the Czech Republic. In both cases, the observed TFR for first births suggests a childlessness of about, and the adjusted TFRs indicate a significantly higher level of first-birth fertility. The same also pertains to the overall TFR, where the observed TFR indicates lowest-low fertility levels and the adjusted TFRs suggest somewhat higher levels between 1.4 and 1.8. However, there are also important differences between the $\mathrm{BF}$ and $\mathrm{KO}$ adjustment, and except for second births in the Czech Republic, the BF-adjusted TFR exceeds the KO-adjusted TFR by $4-36 \%$ on the parity-specific and by $6.8 \%$ (Italy) and $17 \%$ (Czech R.) on the overall level. These differences result from the estimation of tempo changes based on either incidence rates (BF) or childbearing intensities (KO), and our arguments suggests that the former calculations lead to an "over-adjustment" in the above example due to distortions in the estimation (for related discussion, see also Smallwood et al. 2000; van Imhoff and Keilman 2000).

The third and final factor in our decomposition, the effect of parity composition, can be removed by using the period fertility index that is calculated from the multiplicative fertility table (see Section 4). We can then define a parity distribution effect, denoted $d$, as

$$
d=\frac{\mathrm{TFR}^{\prime \prime}}{\mathrm{TFR}}-1
$$

that is, as the ratio of the KO-adjusted period total fertility rate, TFR", which is affected by the period parity composition, and the period fertility index, PF, that is not affected by this parity composition. The parity distribution effect $d$ is positive when the parity composition is favourable to high fertility and therefore increases the total fertility rate as compared to the stable population. It is negative if the parity composition is decreasing the TFR as compared to the stable population, and is zero if the period parity distribution by age is equal to the equilibrium distribution. As is the case for the tempo effect, the parity distribution effect can be defined separately for the different parities and also for each age-parity combination (see Ortega and Kohler 2002). If a fertility regime - defined in terms of childbearing intensities-prevails for a sufficiently long time, the parity composition of the population converges to the equilibrium distribution and the equalities TFR $=\mathrm{TFR}^{\prime \prime}=\mathrm{PF}$ and $d=0$ hold. 
The above factors in Eqs. (7-8), which account for the influence of age structure, parity composition and tempo distortions on period fertility, therefore provide a coherent decomposition of the observed TFR into its demographic components as

$$
\mathrm{TFR}_{t}=\left(1-r_{t}\right) \cdot\left(1+d_{t}\right) \cdot \mathrm{PF}_{t}
$$

where $r_{t}$ is the mean tempo effect, $d_{t}$ is the distribution effect, and $\mathrm{PF}_{t}$ is the period fertility index in calendar year $t$. Moreover, combining this expression with the mean generation size $G_{t}$, we obtain a direct relation between the period fertility index and the number of births in a calendar year as

$$
B_{t}=G_{t} \cdot\left(1-r_{t}\right) \cdot\left(1+d_{t}\right) \cdot \mathrm{PF}_{t}
$$

The number of births is thus derived from the period fertility index by considering three factors: the parity distribution effect $d_{t}$, the tempo effect $r_{t}$, and the mean generation size $G_{t}$.

The period fertility index in this decomposition is a measure of the quantum of fertility since it is equal to the completed fertility of a synthetic cohort experiencing the tempo-adjusted period childbearing intensities. The tempo effect then reflects the extent to which the timing of fertility is changing during a calendar year, and $r_{t}$ expresses the influence of these tempo changes on fertility as the fraction of births that are "missing" $(r>0)$ or "in excess" $(r<0)$ in the year due to a postponement or anticipation of childbearing. The distribution effect summarises the influence of the population parity distribution on period fertility, and it expresses this influence as the relative increase $(d>0)$ or decrease $(d<0)$ in the KO-adjusted total fertility rate due to the fact that the parity distribution in a calendar year is less (more) favourable to fertility than the equilibrium distribution in the stable population. Finally, the mean generation size relates the period TFR to the number of birth in a calendar year. The decomposition in Eq. (10) therefore provides a direct link between the period fertility index (PF) that measures the quantum of fertility and the number of births that occur in a calendar year. Trends in the annual size of the birth cohort can therefore be immediately decomposed into the different factors contributing to the partition in Eq. (10): the quantum of fertility, the timing of fertility, the parity distribution and the mean generation size. ${ }^{8}$

8 A minor caveat of the above decomposition is the sensitivity of the partition to the sequence of operations. The partition is different if the effect of parity distribution is removed before the tempo effect, which is also possible. For instance, one reviewer of this paper suggested to use the order "age, parity-composition, tempo", since the first two effects are statistical while the third effect is behavioural. We prefer the decomposition in Eqs. 13-14 because the interpretation of the tempo effect refers to the actual proportion of births being missed and is thus closely related to the $\mathrm{BF}$ and $\mathrm{KP}$ tempo adjustments. 
Table 6:

Decomposition of the total fertility rate and number of births in period fertility index, parity distribution effect and mean tempo effect

\begin{tabular}{|c|c|c|c|c|}
\hline & \multicolumn{2}{|c|}{ Italy } & \multicolumn{2}{|c|}{ Czech Republic } \\
\hline & 1985 & 1995 & 1985 & 1995 \\
\hline \multicolumn{5}{|l|}{ First births } \\
\hline Conditional parity progression probability $p_{0}$ & 0.864 & 0.808 & 0.926 & 0.905 \\
\hline Parity Distribution effect $d$ & -0.002 & -0.063 & 0.033 & -0.090 \\
\hline KO-adj. TFR & 0.862 & 0.756 & 0.957 & 0.824 \\
\hline Mean tempo effect $r$ & 0.239 & 0.194 & 0.039 & 0.326 \\
\hline Observed TFR & 0.656 & 0.610 & 0.920 & 0.555 \\
\hline Mean generation size $G \times 1000^{-1}$ & 418.7 & 440.2 & 68.1 & 80.2 \\
\hline \# of births $\times 1000^{-1}$ & 274.5 & 268.5 & 62.7 & 44.5 \\
\hline \multicolumn{5}{|l|}{ All birth orders } \\
\hline Period fertility index PF & 1.627 & 1.425 & 1.978 & 1.632 \\
\hline Parity Distribution effect $d$ & -0.007 & -0.015 & 0.056 & -0.067 \\
\hline KO-adj. TFR & 1.615 & 1.404 & 2.088 & 1.523 \\
\hline Mean tempo effect $r$ & 0.139 & 0.157 & 0.072 & 0.177 \\
\hline observed TFR & 1.391 & 1.184 & 1.937 & 1.254 \\
\hline Mean generation size $G \times 1000^{-1}$ & 415.0 & 443.9 & 70.2 & 76.6 \\
\hline$\#$ of births $\times 1000^{-1}$ & 577.3 & 525.6 & 135.9 & 96.1 \\
\hline
\end{tabular}

Source: Council of Europe (2000) for number of birth; own calculations based on ODE data for decomposition

Table 6 provides the decomposition of the total fertility rate and the number of births in Eqs. (13-14) for Italy and the Czech Republic for 1985 and 1995. The first row reveals the conditional parity progression probability, $p_{0}(\alpha, \omega)$ or $p_{0}$, which is our measure of the quantum of first-birth fertility in a calendar year. The probability exceeds the corresponding total fertility rate for first births by more than $30 \%$ in Italy in both 1985 and 1995, and it exceeds the TFR 0 by 65\% in the Czech Republic in 1995. These differences between the observed TFR and the quantum of first-birth fertility can be accounted for as follows. In Italy, there has been only a modest reduction due to a parity distribution effect in 1985, and the KO-adjusted TFR is almost equal to $p_{0}$; however, there has been a substantial mean tempo effect, and the changes in the timing of fertility reduced the Italian period total fertility by almost $24 \%$. In 1995, the parity distribution has become more unfavourable to first-birth fertility in Italy due to the recent decline and delay of fertility, and the parity distribution prevailing in 1995 implies that the KO-adjusted TFR is reduced by $6.3 \%$ as compared to the conditional progression probability. At the same time, the mean tempo effect has slightly diminished in 1995 as compared to a decade earlier, and the reduction in the total fertility rate due to timing changes is "only" $19.4 \%$. In combination, these fac- 
tors have caused a decline in the total fertility rate for first births by almost 7\% during 1985-95. The effects of this decline on the actual number of first births in 1995, however, has been partially compensated by a larger mean generation size that is due to more women at primary childbearing ages, and as a result, the number of first births in 1995 is only $2 \%$ below that of 1985 .

The Czech pattern in 1985 is characterised by an observed total fertility rate for first birth that is almost equal to the period quantum. In 1995, however, a substantial gap between these two measures arises. This wedge between the observed fertility level and the quantum of first-birth fertility is due to a depressing effect of a parity distribution effect $(d=-9 \%)$ and a large mean tempo effect $(r=33 \%)$. In the Czech case, the depressing effects of tempo changes and parity distribution on first-birth fertility are only partially compensated by an increased mean generation size, and there has thus been a decline in the number of first births by 29\% during 1985-95.

The parity distribution effect for first births in the Czech Republic is consistent with our earlier examples demonstrating the disadvantages of using period incidence rates (Section 3): if there is a marked decline in the quantum of first-birth fertility, potentially combined with a postponement of fertility, the parity distribution becomes unfavourable to fertility because many women in childbearing ages will have had their children when fertility was higher and earlier. This exerts a depressing effect on period fertility measures based on incidence rates, such as the TFR for first births. If the current fertility pattern, defined in terms of childbearing intensities, prevails for a sufficiently long time, there will thus be an increase in the KO-adjusted total fertility rate (and also in the observed TFR) because more women will be at risk of having their first child at higher ages.

The bottom part of Table 6 performs the same decomposition for all birth orders combined, and in many ways the result are quite similar. There has been virtually no parity distribution effect in Italy in 1985, and the observed total fertility rate is below the period quantum primarily due to tempo changes $(r=13.9 \%)$. In 1995, there has been a further decline in the Italian period fertility index by $12 \%$ as compared to 1985. The observed TFR, however, has decreased by almost $15 \%$ because both factors, the mean tempo effect and the parity distribution effect, exert a stronger depressing effect on the total fertility rate in 1995 as compared to 1985. In particular, the parity composition effect has risen in magnitude to $d=-1.5 \%$ and the fertility postponement has lead to a larger mean tempo effect of $r=15.7 \%$.

In the Czech Republic, the overall parity distribution effect in 1985 was slightly favourable to fertility $(d=5.6 \%)$, and in addition, there has only been a very week mean tempo effect $(r=7 \%)$. These factors thus compensate each other, and the observed TFR in 1985 was only slightly below the period quantum of $\mathrm{PF}=1.98$. The situation changes substantially in 1995 . While the quantum of fertility declines by about $17 \%$ to 1.63 during $1985-95$, the observed total fertility rate declines by $35 \%$ to a lowest-low level of 1.25. This larger decline in the TFR is caused by two factors: first, the emergence of an unfavourable parity distribution with "too few" women at low parities, and second, the onset of a rapid postponement of fertility that gives rise 
to a mean tempo effect of $17.7 \%$. While the effect of the TFR decline on the total number of births was partially compensated by an increased mean generation size, there has nevertheless been a marked decline in the number of births by almost $30 \%$ during 1985-95.

\section{Cohort fertility}

The investigation of fertility behaviour of individuals born in the same calendar year is the realm of cohort analyses, and the property of tracing roughly the same group of individuals over time is the primary reason that renders these investigations attractive. However, all measures discussed in the previous sections (Sections 4 and 5) are period measures that apply to synthetic cohorts, and these measures do not necessarily reflect the fertility pattern of any real cohort of individuals. An important advantage of the $\mathrm{KO}$ approach discussed in this paper is that all life-table measures of fertility, initially presented in Section 4 for the application to period analyses, are also available for investigating cohort fertility. The only difference for cohort studies is that the tempo-adjusted childbearing intensities $m_{j}^{\prime}(a)$ and tempo-adjusted incidence rates $f_{j}^{\prime}(a)$ need to be replaced with their observed counterparts $m_{j}(a)$ and $f_{j}(a)$. This is necessary since tempo distortions on the level of fertility rates-either incidence rates or childbearing intensities - are not relevant in the study of cohort fertility: even if there are changes in the timing of fertility, fertility rates obtained for cohorts reflect the proper birth rates by which women progress from one to the next parity.

\section{Cohort completion: bridging the gap between period and cohort fertility}

The parity progression approach to cohort completion is based on the idea that the most relevant way of obtaining information about the future fertility behaviour of women still in their childbearing years is to look at the behaviour of women at the relevant ages and parities in the most recent periods for which data are available. That is, future childbearing behaviour of women is described by projecting the current ageand parity-specific period pattern in an appropriate manner on future cohort behaviour. Early examples of this approach towards the completion of cohort fertility are Akers (1965) and Ryder (1980, 1986), which are based on the last period intensities conditional on parity, marital status and/or birth interval.

The primary task in completing cohort fertility based on parity progression measures is the extrapolation and projection of the childbearing intensities experienced by cohorts during the future reproductive years. Moreover, in order to base this projection of childbearing intensities on the past evolution of intensity schedules, it is necessary to establish a relation between $(a)$ the childbearing intensities experienced 
by cohorts in future years and $(b)$ the adjusted intensity schedule in a reference year $T$, where the reference year is usually the last calendar year for which period childbearing intensities are available.

Since the KO approach to tempo adjustment-similar to the BF and KP adjustment-assumes that the adjusted intensity schedule is the product of a period-specific level effect, $q_{j}(t)$, and an age pattern of childbearing intensities, $m_{j}(a, t)$, that can shift to younger or older ages, these two determinants, combined with specific assumptions about future tempo and quantum changes, can be used to characterise the intensities experienced by cohorts in the future. KO can therefore provide general formulas for cohort completion conditional on the parity-specific quantum effect in the reference year and an arbitrary postponement scenario. While this approach can be applied to any given set of postponement/quantum pattern, KO concentrate on two particular benchmark scenarios: In the postponement stops scenario it is assumed that any postponement that occurs in the reference year $T$ comes to a halt and that there is no further postponement of fertility during the remaining life-course of a cohort under consideration. In contrast, the postponement continues scenario assumes that the mean and variance changes observed in the reference year $T$ prevail in the future. The period intensity schedule therefore continues to be shifted to later ages during the life-course of cohorts who are still in their childbearing years, and the annual extent of the shift equals the mean and variance change observed in the reference year $T$. Both scenarios assume that the parity-specific quantum in the reference year continues to prevail in the future for all $t \geq T$.

The formal development of the KO framework that facilitates these different scenarios is discussed in detail in (Kohler and Ortega 2002). The basic insights, however, are conveyed quite easily. In particular, the postponement continues scenario is conceptually the same as introducing tempo and variance changes back into the future evolution of childbearing intensities, holding parity-specific quantum constant, and the future annual mean and variances changes are equal to those estimated in the reference year $T$. As a consequence of this re-introduction of tempo changes in the future evolution of the period intensity schedules, the mean age and variance of the adjusted schedule change over time and are given by

$$
\begin{aligned}
\bar{a}_{j}^{m}(t) & =\bar{a}_{j}^{m}(T)+\gamma_{j}^{m} \cdot(t-T) \\
\operatorname{Var}_{j}^{m}(t) & =\operatorname{Var}_{j}^{m}(T) \cdot \exp \left(2 \delta_{j}^{m} \cdot(t-T)\right),
\end{aligned}
$$

where $\bar{a}_{j}^{m}(T)$ is the mean and $\operatorname{Var}_{j}^{m}(T)$ is the variance of the adjusted intensity schedule in the reference year, and $\bar{a}_{j}^{m}(t)$ and $\operatorname{Var}_{j}^{m}(t)$ describe the evolution of this mean and variance over time for $t \geq T$. The mean and variance change in the above relations, $\gamma_{j}^{m}$ and $\delta_{j}^{m}$, that determine the future timing of fertility can be specified by the analyst; for example, in the postponement stops scenario proposed by KO they are equal to zero, while in the postponement continues scenario they are equal to the mean and variance change observed in the reference year $T$. The above relations can then be used to transform the adjusted intensity schedule in the reference year $T$ into an adjusted intensity schedule $m_{j}^{\prime}(a, t)$ for some future year $t$ that has mean $\bar{a}_{j}^{m}(t)$ and 
variance $\operatorname{Var}_{j}^{m}(t)$. The observed childbearing intensities - which are experienced by cohorts at time $t$ - can be derived from this adjusted schedule using the relation $m_{j}(a, t)=\left(1-r_{j}^{m}(a, t)\right) \cdot m_{j}^{\prime}(a, t)$, where $r_{j}^{m}(a, t)=\gamma_{j}^{m}(T)+\delta_{j}^{m}(T) \cdot\left(\mathrm{a}-\bar{a}_{j}^{m}(t)\right)$.

In summary, the $\mathrm{KO}$ approach to cohort completion constitutes an improvement over previous parity progression projections in the explicit consideration of tempo.

\section{Figure 3:}

Italy: Projection of fertility behaviour for cohorts who have not finished childbearing in 1996 based on the level of fertility and postponement pattern observed in 1996

(a) Proportion still childless at time $t$

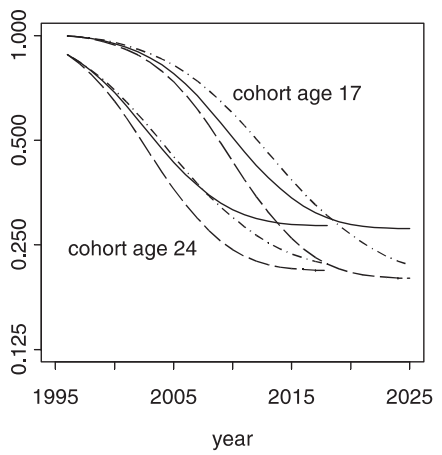

(c) Cumulative cohort fertility

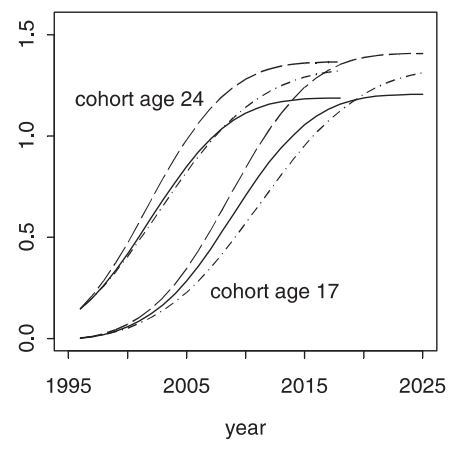

(b) Prop. remaining ultimately childless

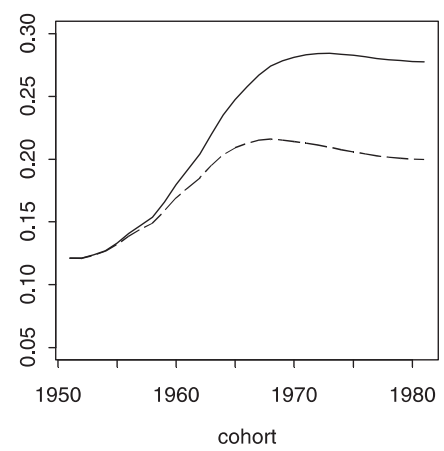

(d) Completed fertility

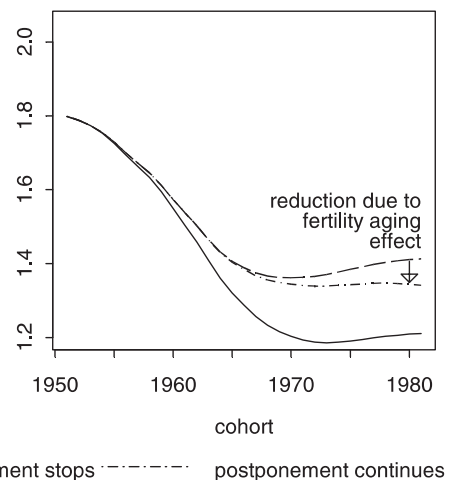

Notes: The postponement stops (dashed line) and postponement continues (dashed-dotted line) are based on the tempo-adjusted fertility intensities and assume either no further delays in childbearing or a further delay in childbearing that mirrors the 1996 postponement pattern. In Graph $(b)$ these two postponement scenarios imply identical results and are not distinguished from each other. The full line in all graphs indicates the projection obtained from the observed fertility intensities.

A key advantage in this context is the ability to incorporate different postponement scenarios, enabling the $\mathrm{KO}$ approach to account for two distinct implications caused by delays in childbearing. On the one hand, tempo distortions lead to an underestimation of the probability that women experience another birth conditional on their current age and parity. On the other hand, the presence of a fertility postponement de- 
lays the age at which women are exposed to the risk of higher parity births. This can potentially lead to a reduction of the progression to higher parities, which we denote as the fertility ageing effect associated with a postponement of childbearing. This effect can be partially or totally compensated for if the fertility schedule at higher parities is shifted as a response to the postponement at lower parities.

Figure 4:

Czech Republic: Projection of fertility behaviour for cohorts who have not finished childbearing in 1999 based on the level of fertility and postponement pattern observed in 1999

(a) Proportion still childless at time $t$

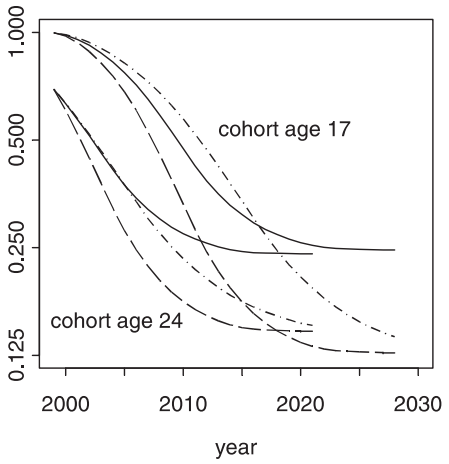

(c) Cumulative cohort fertility

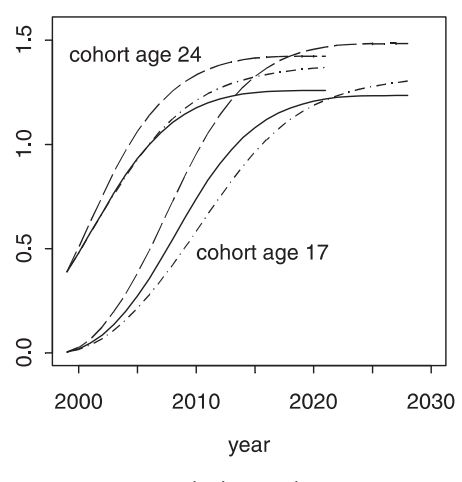

proj. observed (b) Prop. remaining ultimately childless

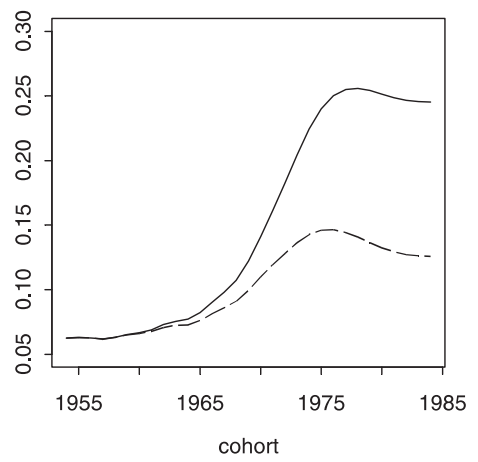

(d) Completed fertility

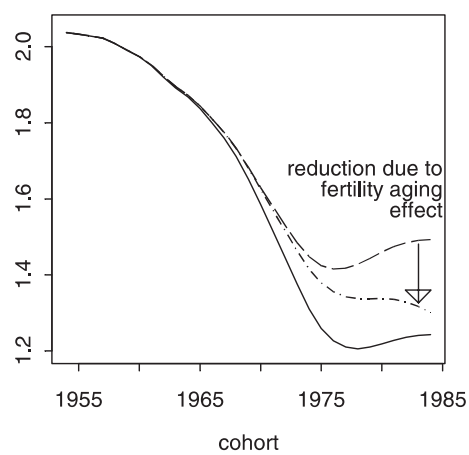

postponement continues

See Figure 3 for notes.

The study of fertility ageing effects is feasible within the KO framework by comparing the cohort completion under the postponement continues and the postponement stops scenarios. We illustrate this analysis for Italy and the Czech Republic in Figures 3 and 4 using reconstructed cohort data provided by the Observatoire Démographique Européen. In Figures 3(a) and 4(a), for instance, we consider the cohorts who are 17 and 24 years old in 1996 (Italy) and 1999 (Czech Republic), each of which constitutes the most recent period data available. The analyses then project the proportion of women who will still be childless in the years $2000,2005,2010 \ldots$, un- 
der the assumption that the 1996/1999 parity-specific fertility quantum is to prevail in the future. These calculations are augmented in Figures 3(b) and 4(b) with the projected level of final childlessness in all cohorts who are still in childbearing ages in 1996/1999.

The full line in these two figures reflects the transition into parenthood that is obtained from the observed childbearing intensities, and these calculations project an ultimate level of childlessness around 28\% in Italy and 25\% in the Czech Republic. However, because the pace of fertility postponement has been quite high during the 1990s in these countries, this projection is distorted by tempo effects and does not reflect the true cohort experience that is implied by the 1996/1999 level of fertility. The unbiased calculations based on the adjusted childbearing intensities with no further postponement of fertility (dashed lines) project a substantially more rapid transition into parenthood and a substantially lower level of ultimate childlessness of about 20\% (Italy) and 13\% (Czech Republic). Hence, projections based on the observed childbearing intensities, which are tempo-distorted in periods of a fertility postponement, tend to underestimate the fraction of women who are going to experience at least one child given the current level of fertility.

This ultimate level of childlessness in cohorts does not depend on assumptions about future postponement patterns in the KO model. However, important differences exist between the postponement stops and the postponement continues scenario with respect to the timing of entering parenthood. If the postponement of fertility is assumed to continue at the pace observed in 1996 (Italy) or 1999 (Czech Republic), the transition into parenthood is delayed (Figures 3a and 4a). This effect of a continued postponement on the transition into parenthood is more pronounced in the younger cohort because the postponement continues for a prolonged time until this cohort reaches the primary ages of childbearing.

In Figures 3(c) and 4(c) we shift our analysis to the combined fertility across all birth orders and report the cumulative cohort fertility for women who are age 17 and 24 in 1996 or 1999. In both cohorts an ongoing postponement of fertility implies a lower cumulative fertility in all future years as compared to the postponement stops scenario. This pattern is due to two factors. On the one hand, entry into parenthood is postponed towards older ages. On the other hand, the delayed onset of parenthood shifts the beginning of being 'at risk' of a second and higher order births even further, and at these relatively old ages the probability of experiencing a second or third birth declines rapidly. Corresponding calculations from observed childbearing intensities suggest a cumulative fertility that is below the postponement stops scenario, and this difference is due to the tempo distortions in the observed period intensities. However, the relation is no longer as clear-cut if the postponement of fertility is assumed to continue. In particular, the observed intensities and the postponement continues scenario imply an approximately equal cumulative fertility until about 2008 in the cohort aged 24, and afterwards a continued postponement suggests a higher cumulative fertility due to some late first and higher order births. In the cohort aged 17 in 1996/1999, the postponement continues scenario implies a cumulative fertility level 
until about 2020 that is substantially below the level suggested by the observed intensities. Due to relatively late childbearing the completed fertility in this cohort will exceed the completed fertility suggested by the observed data, but it will fall substantially short of the level attained by the cohort in the postponement stops scenario. This pattern, which is illustrated for the cohorts who are 17 and 24 years old, pertains similarly to all cohorts who have not completed fertility as of 1996/1999 (Figures 3c and $4 \mathrm{c}$ ). While the completed fertility of cohorts reaches a trough for cohorts born around 1970 (Italy) and 1975 (Czech R.) and then increases to levels of 1.4 (Italy) and 1.5 (Czech R.) for young cohorts under the postponement stops scenario, cohort fertility continues to decline in young cohorts if the postponement of fertility continues at the pace observed in 1996/1999. These further declines in the postponement continues scenario are due to a fertility ageing effect: the number of higher order births is reduced by an ongoing delay of childbearing because women tend to be 'at risk' of second and higher order births only at ages when the probability of experiencing second, third, and fourth births is already quite low.

\section{Discussion}

In this article we have provided an overview of traditional and recent methods for the investigation of fertility, emphasising in particular aspects of the analysis that are relevant in contemporary low and lowest-low fertility contexts. For this purpose, we have presented a new approach that integrates traditional measures of fertility, such as the TFR, in a versatile manner with $(a)$ the tempo adjustment of fertility that corrects for distortions due to the rapid postponement of fertility, $(b)$ life-table measures of fertility that eliminate influences caused by the parity composition of the population, and $(c)$ methods for cohort completion and projection that provide a consistent and demographically correct mapping of recent period fertility patterns on the future childbearing behaviour of women still in their childbearing years.

This integration is particularly important for measuring and understanding contemporary fertility trends. First, the separate analysis by parity emerges as a key aspect due to the different socioeconomic contexts and decision-making processes that determine the transition to the first and then higher parity births. Moreover, due the fact that in many low fertility countries a larger proportion of births occur outside marriage, it is also advisable to study births irrespective of marital status and focus on parity instead. In order to make these analyses possible, vital statistics must provide the appropriate tabulation of births, which is not always the case.

Second, we strongly argue in favour of using childbearing intensities, or occurrence-exposure rates, for the analyses of lowest-low fertility instead of incidence rates or rates of the second kind. In particular, childbearing intensities provide an indicator of period fertility behaviour that is not affected by the parity distribution of the population, which reflects past fertility behaviours and trends.

Third, we support earlier research arguing that tempo distortions have to be taken 
into account when the timing of fertility changes over time. The estimation of tempo distortion must be based on explicit models of fertility and tempo change, and we favour in particular the age and parity model as a suitable framework for these analyses. Most importantly, the evolution of intensity schedules in the age and parity models is not affected by parity composition effects, eliminating therefore an important limitation of analyses that are based on incidence rate schedules.

Fourth, we demonstrate that fertility tables calculated from tempo-adjusted childbearing intensities enable researchers to isolate the behaviour determinants of period fertility from influences due to parity composition and tempo effects. In particular, we propose the period fertility index, which reflects the completed fertility of a synthetic cohort experiencing the tempo-adjusted period childbearing intensities, as a natural measure of the overall quantum of fertility in a calendar year, and we suggest the conditional parity progression probability as the corresponding indicator of the parity-specific quantum.

Fifth, the above measures provide a decomposition of the total fertility rate into three factors, including a mean tempo effect, a parity distribution effect and the period fertility index. Adding the mean generation size, this decomposition provides a direct link between the indicator of period quantum, the period fertility index, and the number of births that occur in a calendar year. This analysis can therefore reveal the extent to which the number of births in a year is affected by current fertility behaviour of individuals, past fertility behaviour manifested in the population parity distribution in a calendar year, and tempo changes due to contemporaneous changes in individuals' timing of fertility.

Sixth, we propose the KO approach for cohort completion. In particular, this approach uses the most recent parity- and age-specific period fertility behaviour and projects these period fertility pattern on future childbearing behaviours of cohorts who are still in their childbearing years. This analysis is possible under different scenarios for the future evolution of the tempo and quantum of fertility. In addition to projecting future cohort fertility, this approach thus enables the investigation of fertility ageing effects, that is, potential reductions in completed fertility due to an ongoing delay of childbearing that shifts the exposure to higher parity births to ages at which the respective progression probabilities for an additional child are quite low.

In summary, the measures described in this paper provide a unified toolkit that allows (a) the description and analyses of period fertility patterns in terms of synthetic cohort measures that are closely linked to individuals' fertility behaviour and corrected for tempo distortions, $(b)$ a decomposition of changes in the total fertility rate and annual size of the birth cohort into trends in the quantum and timing of fertility as well as fluctuations in the population parity distribution, and (c) the demographically correct projection of cohort fertility under different scenarios about the future tempo and quantum of fertility. 


\section{Acknowledgments}

We appreciate the support by the Spanish Ministry of Science and Technology that has partially funded the research on this paper through Project SEC2002-00610. We are also indebted to the Max Planck Institute for Demographic Research for the support provided for this paper and prior research on which we draw in our discussion. The data used in the analyses in this paper have been generously provided by the Observatoire Démographique Européen (through the Max Planck Institute for Demographic Research). We also gratefully acknowledge the permission by Demographic Research to draw in this paper on materials that were previously published in H.-P. Kohler and J. A. Ortega "Tempo-Adjusted Period Parity Progression Measures, Fertility Postponement and Completed Cohort Fertility." Demographic Research 6(6), 91-144.

\section{References}

Akers, D. S. 1965. Cohort fertility versus parity progression as methods of projecting births. Demography 2(1-2), pp. 414-428.

Bongaarts, J. and G. Feeney. 1998. On the quantum and tempo of fertility. Population and Development Review 24(2), pp. 271-291.

Bongaarts, J. and G. Feeney. 2000. On the quantum and tempo of fertility: Reply. Population and Development Review 26(3), pp. 560-564.

Borgan, O. and H. Ramlau-Hansen. 1985. Demographic incidence rates and estimation of intensities with incomplete information. Annals of Statistics 13(2), pp. 564-582.

Calot, G. 1984. Une notion intéressante: L'effectif moyen des générations soumises au risque. I. Présentation méthodologique. Population 39(6), pp. 947-976. (Translated into English in Population, English Selection, 39(6), pp. 947-976 (1984)).

Calot, G. 1985. Une notion intéressante: L'effectif moyen des générations soumises au risque. II. Quelques exemples d'application. Population 40(1), pp. 103-130. (Translated into English in Population, English Selection, 40(1), pp. 103-130 (1985)).

Calot, G. 2001a. Mais qu'est-ce donce qu'unindicateur conjuncturel de fécondité. Population 56(3), pp. 325-327.

Calot, G. 2001b. Pourquoi la notion de „replacement transversal“ est essentielle. Population 56(3), pp. 329-331.

Council of Europe 2000. Recent Demographic Developments in Europe. Strasbourg: Council of Europe Publishing.

De Simoni, A. 1995. Misure di sintesi della fecondità del momenta per ordine di nascita. applicazione al caso Italiano. Genus 51(1-2), pp. 105-131. 
Feeney, G. and J. Yu. 1987. Period parity progression measures of fertility in China. Population Studies 41(1), pp. 77-102.

Feichtinger, G. 1987. The statistical measurement of the family life circle. In: Bongaarts, J., T. Burch, and K. Wachter. (eds), Family Demography. Methods and their Applications. Oxford: Oxford University Press, pp. 81-101.

Finnäs, F. 1980. A method to estimate demographic intensities via cumulative incidence rates. Theoretical Population Biology 17, pp. 365-379.

Giorgi, P. 1993. Una rilettura della fecindità del momento per ordine de nascita in Italia nel periodo 1950-1990 considerando la struttura per parità. Genus 49(3-4), pp. 177-204.

Heckman, J. J. 2001. Econometrics counterfactuals and causal models. Keynote address, International Statistical Institute, Seoul, South Korea, August 27, 2001.

Hoem, J. M. 1978. Demographic incidence rates. Theoretical Population Biology 14(3), pp. 329-337.

Kim, Y. J. and R. Schoen. 2000. On the quantum and tempo of fertility: Limits to the Bongaarts-Feeney adjustment. Population and Development Review 26(3), pp. 554-559.

Kohler, H.-P. and J. A. Ortega. 2002. Tempo-adjusted period parity progression measures, fertility postponement and completed cohort fertility. Demographic Research [online available at http://www.demographic-research.org] 6(6), pp. 91-144.

Kohler, H.-P. and D. Philipov. 2001. Variance effects in the Bongaarts-Feeney formula. Demography 38(1), pp. 1-16.

Kuczynski, R. 1932. Fertility and Reproduction. Methods of Measuring the Balance between Births and Deaths. New York: Falcon Press.

Lotka, A. J. and M. Spiegelman. 1940. The trend of the birth rate by age of mother and order of birth. Journal of the American Statistical Association 35(212), pp. 595-601.

Lutz, W. 1989. Distributional Aspects of Human Fertility: A Global Comparative Study. New York: Academic Press.

Ortega, J. A. and H.-P. Kohler. 2002. A new look at period fertility: A decomposition of the effects of parity distribution, tempo distortions and fertility on the period TFR. Mimeo, Max Planck Institute for Demographic Research, Rostock, Germany.

Park, C. B. 1976. Lifetime probability of additional births by age and parity for American women, 1935-1968: A new measurement of period fertility. Demography 13(1), pp. 1-17.

Quensel, C.-E. 1939. Changes in fertility following birth restriction. Skandinavisk Aktuarietidskrift 22(3-4), pp. 177-199.

Rallu, J.-L. and L. Toulemon. 1993a. Les mesures de la fécondité transversale I. Construction des differénts indices. Population 48(1), pp. 7-26. 
Rallu, J.-L. and L. Toulemon. 1993b. Les mesures de la fécondité transversale II. Application á la France de 1946 á 1989. Population 48(2), pp. 369-404.

Rallu, J.-L. and L. Toulemon. 1994. Period fertility measures: The construction of different indices and their application to France, 1946-89. Population: An English Selection 6, pp. 59-130.

Ryder, N. B. 1964. The process of demographic translation. Demography 1(1), pp. $74-82$.

Ryder, N. B. 1980. Components of temporal variations in American fertility. In: Hiorns, R. W. (ed), Demographic Patterns in Developed Societies. London: Taylor and Francis, pp. 15-54.

Ryder, N. B. 1986. Observations on the history of cohort fertility in the United States. Population and Development Review 12(4), pp. 617-643.

Schoen, R. and S. H. Jonsson. 2003. A diminishing population whose every cohort more than replaces itself. Demographic Research [online available at http://www.demographic-research.org] 9(6), pp. 112-118.

Smallwood, S., M. Murphy, and A. Gjonca. 2000. Alternative approaches to the analysis of fertility trends in lowest low fertility countries, and their application to British and Swiss data. London School of Economics, Mimeo.

Toulemon, L. 2001. Why fertility is not so low in France. Paper presented at the IUSSP Seminar on International Perspectives on Low Fertility: Trends, Theories and Policies. Tokyo, Japan, March 21-23.

Vallin, J. and G. Caselli. 2001. L'artifice de la cohorte fictive. In: Caselli, G., J. Vallin and G. Wunsch (eds), Démographie: Analyse et Synthèse. I. La Dynamique des Populations. Paris: Éditions de l'INED, pp. 271-327.

van Imhoff, E. 2001. On the impossibility of inferring cohort fertility measures from period fertility measures. Demographic Research [online available at http://www.demographic-research.org] 5(2), pp. 23-64.

van Imhoff, E. and N. Keilman. 1991. LIPRO 2.0: An Application of a Dynamic Demographic Projection Model to Household Structure on the Netherlands. Amsterdam/Lisse: Swets and Zeitlinger. (latest available version: LIPRO 4.0).

van Imhoff, E. and N. Keilman. 2000. On the quantum and tempo of fertility: Comment. Population and Development Review 26(3), pp. 549-553.

Whelpton, P. K. 1946. Reproduction rates adjusted for age, parity, fecundity, and marriage. Journal of the American Statistical Association 41(236), pp. 501-516. 
